\title{
Letter \\ Severe community acquired pneumonia: what should we predict?
}

\section{Bertrand Renaud and Aline Santin}

\author{
Department of Emergency Medicine, Groupe Hospitalier Henri Mondor-Albert Chenevier (AP-HP), Université Paris 12, Faculté de Médecine Créteil, \\ F-94010, France
}

Corresponding author: Bertrand Renaud, bertrand.renaud@hmn.aphp.fr

Published: 15 October 2009

This article is online at http://ccforum.com/content/13/5/421

(c) 2009 BioMed Central Ltd

Several aspects relating to the definition of severe community acquired pneumonia (CAP) and the design of prediction tools need to be addressed prior to further attempts to predict severe CAP.

What is the concept of severe CAP based on? CAP severity could be based on pathophysiological disorders that would allow physicians to objectively define severity. Alternatively, CAP severity could be based on treatment intensity, which would certainly facilitate its uptake and the development of clinical tools to assist physicians in decision-making. This second approach, which seems more clinically relevant, will be assumed for the rest of this letter.

What are the most relevant criteria for severe CAP? Basically, there are two possibilities: admission to ICU or respiratory/circulatory support requirement [1]. The former criterion is often perceived as too vague as it remains a matter of individual judgment [2]. The second is less prone to subjectivity, but may be too restrictive, as intensive care benefit is not limited to patients that require vital support. However, one must keep in mind the final objective of developing prediction tools for severe CAP; in this context, the definition exclusively based on respiratory/hemodynamic support requirement is less restrictive. Therefore, consistent with Chalmers [3], we suggest keeping this second definition of CAP severity.

At this point, several features regarding prediction of severe CAP may be considered. Given the increasing evidence that patients with incipient severe sepsis may benefit from intensive care and from early referral, this prediction would apply to CAP patients presenting to the emergency department with rapidly progressive pneumonia at high risk of developing organ failure but with no overt respiratory/ hemodynamic distress [4]. Indeed, predicting what is obvious is of no value. In contrast, patients that are too sick to be eligible for ICU admission have to be excluded. Additionally,
Critical Care 2009, 13:421 (doi:10.1186/cc8111)

regardless of the 30-day risk of severe CAP after presentation to the emergency department, if the 7-day risk is extremely low, CAP patients could be hospitalized in the wards. By contrast, if the 7-day risk is high, physicians would likely want to provide intensive care. Therefore, the most effective prediction tool would ascertain the risk of severe CAP within a week of presentation and assist physicians in making the critical ICU admission decision [5].

It is time for the medical community to unequivocally define severe CAP with the aim of improving the efficiency of resource utilization and the effectiveness of management strategies for patients that present with moderately severe CAP.

\section{Competing interests}

The authors declare that they have no competing interests.

\section{References}

1. Charles PG, Wolfe R, Whitby M, Fine MJ, Fuller AJ, Stirling $R$, Wright AA, Ramirez JA, Christiansen KJ, Waterer GW, Pierce RJ, Armstrong JG, Korman TM, Holmes P, Obrosky DS, Peyrani P, Johnson B, Hooy M; Australian Community-Acquired Pneumonia Study Collaboration, Grayson ML: SMART-COP: a tool for predicting the need for intensive respiratory or vasopressor support in community-acquired pneumonia. Clin Infect Dis 2008, 47:375-384.

2. Simpson HK, Clancy M, Goldfrad C, Rowan K: Admissions to intensive care units from emergency departments: a descriptive study. Emerg Med J 2005, 22:423-428.

3. Chalmers JD: ICU admission and severity assessment in community-acquired pneumonia. Crit Care 2009, 13:156.

4. Renaud B, Labarère J, Coma E, Santin A, Hayon J, Gurgui M, Camus N, Roupie E, Hémery F, Hervé J, Salloum M, Fine MJ, Brun-Buisson C: Risk stratification of early admission to the intensive care unit of patients with no major criteria of severe community-acquired pneumonia: development of an international prediction rule. Crit Care 2009, 13:R54.

5. Rivers E, Nguyen B, Havstad S, Ressler J, Muzzin A, Knoblich B, Peterson E, Tomlanovich M: Early goal-directed therapy in the treatment of severe sepsis and septic shock. $N$ Engl J Med 2001, 345:1368-1377. 